\title{
Evaluation of the energy recovery potential of thermoelectric generators in diesel engines
}

Rafael Ramírez, Alexis Sagastume Gutiérrez, Juan J. Cabello Eras, Karen Valencia, Brando Hernández, Jorge Duarte Forero

\section{Abstract}

Thermoelectric generation is an alternative to recover some of the wasted energy trough an exhaust of the internal combustion engines. This paper assesses the performance of a thermoelectric generator with 20 modules by implementing a waffle heat exchanger. Experimental results showed a variable range of power recovery from $57.87 \mathrm{~W}$ to $71.13 \mathrm{~W}$ for $\mathrm{B} 10, \mathrm{~B} 5$, and Diesel. The highest energy conversion efficiency of the aforementioned thermoelectric device was of $3 \%$ with the highest load and the fastest rotational speed. Also, the recovery process reduced gaseous emissions such as $\mathrm{CO}, \mathrm{CO}_{2}, \mathrm{NO}, \mathrm{NO}_{\mathrm{x}}$ and $\mathrm{HC}$. Additionally, the smoke opacity per $\mathrm{kWh}$ is reduced at significant levels of operations such as $2.42 \%$ when using diesel, 2.65\% when using B5 and 3\% when using B10. However, when using biodiesel blends, NOx emissions were increased. Overall the biodiesel resulted in a higher power recovery performance versus the diesel.

\section{Keywords}

Energy recovery, Heat exchanger, Thermoelectric generator, Thermoelectric module, Internal combustion engine. 